This is a pre-print version of: Semino, E. (2005). The metaphorical construction of complex domains: the case of speech activity in English. Metaphor and Symbol, 20 (1), 35-69.

\title{
The metaphorical construction of complex domains: the case of speech activity in English ${ }^{1}$
}

\author{
Elena Semino, Lancaster University, UK
}

\begin{abstract}
In this paper I provide an account of the way in which the domain of spoken communication is metaphorically constructed in English, on the basis of the analysis of over 450 metaphorical references to speech activity in a corpus of contemporary written British English. I show how spoken communication is mainly structured via a set of source domains that conventionally apply to a wide variety of target domains, such as the source domains of MOTION, PHYSICAL TRANSFER, PHSYICAL CONSTRUCTION and PHYSICAL SUPPORT. Each of these source domains structures a particular aspect of speech activity, such as the achievement of communicative goals, the expression of meanings and ideas, the performance of speech acts, the negotiation of mutual relationships, and so on. I suggest that the particular conceptual mappings that underlie the main patterns in my data are best seen in terms of Grady's (1997) notion of primary metaphors, i.e. as simple, basic mappings that have a firm experiential basis and that apply to a wide range of different areas of experience (e.g. "HELP/ASSISTANCE IS SUPPORT"). However, I also show that the main primary metaphors involved in structuring the domain of speech activity can be combined into a single overall physical scenario in which interactants can move in different directions, place themselves in different positions in relation to each other, come into contact with each other in different ways, physically produce texts/utterances/speech acts, physically pass texts/utterances/speech acts to each other, and make meanings visible to each other in different ways. Finally, I argue that a corpus-based methodology has much to offer to metaphor research, particularly in the extrapolation of conceptual metaphors from linguistic data.
\end{abstract}

\section{INTRODUCTION}

From the very early days of cognitive metaphor theory, a great deal of attention has been devoted to the way in which speakers of English metaphorically construct the domain of communication in everyday language. Reddy's (1979) account of the "conduit" metaphor influenced most later discussions of metaphors for communication (e.g. Lakoff and Johnson 1980: 10-12; Grady 1997, 1998; Kövecses 2002: 73-4, Taylor 2002: 490), while Lakoff and Johnson's (1980) Metaphors We Live By opened with an equally influential 
discussion of the conceptual metaphor "ARGUMENT IS WAR" . A number of other studies have pointed out further source domains that are conventionally applied, in English, to the domain of communication, including particularly the domain of motion (Sweetser 1987, Kövecses 2002: 80, Goossens et al. 1995, Traugot and Dasher 2002: 190ff.)

In this paper I develop and partly correct the view of the metaphorical construction of communication that has been presented so far, on the basis of the analysis of over 3,500 references to speech activity in a corpus of written British English. I will argue that my analysis provides a more complete (although by no means exhaustive) account of how spoken communication is metaphorically talked about in English, and that this in turn leads to the formulation of more reliable hypotheses about underlying conceptual metaphors than is the case when data is less extensive, less varied, and, in some cases, partly generated by the analyst(s) (see Vanparys 1995: 2-6 for similar considerations).

My main overall finding is that, in my data, speech activity is metaphorically talked about by means of expressions that:

1) Potentially evoke a fairly wide range of different source domains (for example, the use of the verb "attack" in "Delors attacked Balladur's idea of a "Europe of circles" " potentially evokes the domain of PHYSICAL AGGRESSION; the use of the verb "support" in "Mr Milosevic supported the plan then" potentially evokes the domain of PHYSICAL SUPPORT);

2) Are also often used metaphorically to talk about domains of experience other than communication (for example, the verb "attack" can be used to talk about illness in expressions such as "the infection attacks the lymphatic system" from the British National Corpus, hereafter the BNC; the verb "support" can be used to talk about financial contributions in expression such as "Our work in the African continent [. . .] is supported by Tear Fund", from the BNC).

In other words, the highly complex domain of speech activity is, not surprisingly, conventionally structured via a number of different metaphorical source domains. These source domains are not specific to speech activity in particular, but have a very wide metaphorical "scope", i.e. they conventionally apply to a wide range of target domains (Kövecses 2000b, 2002: 108ff.).

The complexity of the particular target domain I am concerned with mostly lies in the fact that speech activity involves a number of different aspects, including, for example, the production of utterances, the performance of illocutionary acts, the expression and exchange of ideas, the expression of agreement or disagreement with others' views, the expression and negotiation of mutual relationships, the achievement of goals via speech, and so on. In my data, each of these different aspects is consistently structured by one or more wide-scope source domain(s). In order to provide a broad overview of my findings, I list below the source domains that feature most prominently in my data, and the aspects of speech activity they conventionally apply to. As I will show in more detail at the end of the paper, the ordering of the list reflects, in descending order, the frequency of occurrence of expressions relating to each particular source domain in my data (N.B unless otherwise indicated, examples are taken from my corpus; the relevant metaphorically used words are underlined): 
- The source domain of TRANSFER (OF OBJECTS) is applied to the expression of meanings, thoughts, ideas (which Reddy 1979 called " repertoire members" or RMs), and to the production of utterances and speech acts (e.g. "Sir Hugh gave his assessment last Monday”);

- The source domain of PHYSICAL CONSTRUCTION (OF OBJECTS) is applied to the production of utterances and speech acts (e.g. "make a comment") and to the further expression of similar meanings and ideas to those that have already been previously expressed (e.g. "But he added: "We need to work out whether the pluses outweigh the minuses");

- The source domain of VISIBILITY/VISUAL REPRESENTATION is applied to the expression of meanings and to the process of enabling others to understand meanings and information (e.g. "I pointed out to David that these people didn't really appreciate their music");

- The source domain of MOVEMENT is applied to the performance of speech acts and to the pursuit of goals via speech (e.g. "Mary's father stepped in with congratulations");

- The source domain of PHYSICAL AGGRESSION is applied to the expression of disagreement and criticism, the attempt to discredit others and their views, and the adoption of a forceful, antagonistic attitude in communication (e.g. "sniping at the Blair style of leadership", "bombarding with questions");

- The source domain of PHYSICAL PROXIMITY is applied to the expression of agreement and solidarity with others and their views (e.g. "Afterwards Mr Milosevic [. . .] backed the proposals");

- The source domain of PHYSICAL PRESSURE is applied to the attempt to achieve particular objectives via speech or to force others to engage in communication (e.g. "the Mirror continued to press him over [. . .]");

- The source domain of PHYSICAL SUPPORT is applied to the expression of agreement and solidarity with others and their views or proposals (e.g. "Mr Milosevic supported the plan then").

In his work on complex target domains such as friendship and happiness, Kövecses (2000: 87ff.; 2002: 84ff.) similarly found that they are structured by a set of source domains with a very wide metaphorical scope, each applying to a particular aspect of the relevant emotion concept. ${ }^{2}$

My findings can also be expressed in terms of Grady's notion of "primary metaphors", which are defined as simple, basic mappings that (i) have a strong experiential basis, (ii) motivate metaphorical expressions that can be applied to different domains of experience, and (iii) combine to produce many different complex metaphors (see Grady 1997, 1999). For example, the primary metaphor "HELP IS SUPPORT" can explain the metaphorical use of the verb "support" in relation to communication (as in "Mr Milosevic supported the plan then") and in relation to other contexts (as in "Our work in the African continent [. . . ] is supported by Tear Fund", from the BNC). Similarly, the primary metaphor "DAMAGE IS PHYSICAL HARM" can be said to underlie the metaphorical use of the verb "attack" in relation to communication (as in "Delors attacked Balladur's idea of a "Europe of Circles"”) and in relation to many other contexts (as in "the infection attacks 
the lymphatic system", from the BNC). Within this perspective, a large part of my data can be explained in terms of a range primary metaphors that are not specific to communication in particular, but which combine to form "complex" metaphors for communication (e.g. "ANTAGONISTIC COMMUNICATION IS PHYSICAL AGGRESSION"). At the end of the paper I will show how these metaphors, although not always compatible with each other, can be combined to form a single overall conceptualization of spoken communication in terms of a physical scenario; within this scenario, interactants can stand in different positions, move in different directions, come into physical contact or conflict in different ways, construct their utterances/speech acts, pass their utterances/speech acts on to others, or make meanings visible to others in different ways.

These two approaches to the analysis of my data (i.e. via a set of wide-scope source domains or via a set of primary metaphors) are not at all incompatible with each other. Indeed, Kövecses (2002: 109ff.) argues that each wide-scope source domain has a "major theme" or "main meaning focus", which he describes as "the culturally agreed-on conceptual material associated with the source that it conventionally imparts to its targets" (Kövecses 2002: 118). The main meaning focus of each source domain gives rise to small number of "central mappings", whereby its most culturally salient and distinctive aspects structure some aspects of a wide variety of target domains (Kövecses 2002: 11012). Kövecses explains that these central mappings can be seen as "simple" conceptual metaphors that combine to form "complex" conceptual metaphors, and explicitly equates these simple metaphors/central mappings with Grady's primary metaphors (Kövecses 2002: 111). In evaluating this equivalence, it is important to note that Grady and Kövecses adopt slightly different criteria and methods for determining simple/primary metaphors: Kövecses tends to start from large, wide-scope source domains (e.g. FIRE), from which he derives "simple" metaphors (e.g. "THE HIGHEST DEGREE OF INTENSITY IS THE HIGHEST DEGREE OF HEAT" and “CHANGE OF INTENSITY IS CHANGE OF HEAT"); in contrast, Grady tends to start from patterns of metaphorical expressions that apply to a wide range of target domains (e.g. "Trading has really heated up this week", "Things have cooled down at the paper since the election", Grady 1997: 290) in order to arrive at "primary" metaphors (e.g. "INTENSITY OF ACTIVITY IS HEAT"). As a consequence of these methodological differences, the two approaches may not always arrive at exactly the same conclusions, but Kövecses (2002: 110-12) does show significant convergence of results in a number of cases.

For the purposes of this paper, I will divide my analysis into sections on the basis of the most prominent source domains listed above, since this affords a useful overall view of the main general patterns I have found in my data. However, in explaining specific groups of examples, I will mostly refer to primary metaphors, for two main reasons: first, my "bottom-up" methodology is particularly compatible with Grady's approach; second, a considerable part of my data can be best accounted for in terms of some of the primary metaphors Grady has already proposed (Grady 1997, 1998), even though he did not always explicitly mention their relevance to the domain of (spoken) communication. As I go along, I will also point out how many relevant source domains have an imageschematic basis (see Pauwels and Simon-Vanderbergen 1995 for a detailed discussion), which also supports the overall claim that the complex domain of speech activity is 
primarily constructed in terms of a relatively small set of basic, "multi-purpose" mappings.

\section{THE DATA}

My data was extracted from a corpus that was constructed and annotated for speech, writing, and thought presentation (hereafter SW\&TP) by a team working at Lancaster University in the 1990s (see Wynne et al. 1998, Semino et al. 1999, Semino and Short 2004). It contains 120 text samples of approximately 2,000 words each, amounting to a total of 258,348 words of (late) $20^{\text {th }}$ century written British English. The corpus is equally divided into three main genre sections: prose fiction (87,709 words); newspaper news reports ( 83,603 words); and biography and autobiography (87,036 words). The genres were selected as prime examples of fictional and non-fictional narrative text-types, since the presentation of others' words and thoughts is particularly central, although not exclusive to, narrative texts. Each of the three genre sections is in turn equally divided into a "serious" and a "popular" sub-section. For example, in the newspaper section of the corpus, half the samples are taken from broadsheet newspapers and half from tabloid newspapers. For the other two genres, a number of criteria were applied in order to include equal amounts of extracts from popular as opposed to serious books (see Semino et al. 1999 and Semino and Short 2004: 19ff. for our criteria in implementing these distinctions).

The corpus was manually annotated for categories of SW\&TP, such as Direct Speech, Free Indirect Thought, and so on. I do not have the space here to describe the annotation system we applied to the corpus (but see Wynne et al. 1998 and Semino and Short 2004: $26 \mathrm{ff}$. for a detailed discussion). What is relevant for the purposes of this paper is that the availability of an annotated corpus makes it possible to obtain concordances for each of the categories of SW\&TP included within the annotation system. Here I will focus on two particular textual phenomena that were captured by our annotation system, namely the speech presentation category known as the "Narrator's Representation of Speech Acts" (NRSA), and speech reporting clauses.

The NRSA category, which was originally introduced in Leech and Short (1981), captures those expressions which report one or more utterances by referring to their (supposed) illocutionary force or speech act value. The following is a prototypical example from the newspaper section of the corpus:

1. At one point during negotiations, [ . . ] he demanded a helicopter (The Daily Telegraph, 29/4/1996)

NRSAs typically include a verb referring to a speech act (e.g. demand in example 1), and a noun phrase or prepositional phrase providing an indication of the content of the relevant utterance (e.g. a helicopter in example 1). NRSAs can also be realized by noun phrases where the head noun refer to a speech act (e.g. demands for tighter gun controls). 
In practice, the scope of the NRSA tag also includes some expressions that do not refer to speech act values in the strictest sense, but to speech activity more generally. The use of the verbs "attack" and "support" in expressions such as "Delors attacked Balladur's idea of ..." and "Mr Milosevic supported the plan then", for example, cannot be easily accommodated within classifications that are based on a strict definition of (verbs referring to) illocutionary force (e.g. (Austin 1962, Searle 1979, Bach and Harnish 1979). Expressions such as these can, however, be accounted for within Ballmer and Brennenstuhl's (1981) Speech Act Classification, which includes "any kind of (aspect of) speech activity designating verb", for a total of 4,800 expressions (Ballmer and Brennenstuhl 1981: 16). This, they argue, results in "a more relevant class of expressions with respect to linguistic behaviour than the 'performative' verbs" (Ballmer and Brennenstuhl 1981: 16).

The main formal criterion for the application of the NRSA tag was that there was no grammatical separation between a reporting clause and a reported clause, since this structure is typical of the category of Indirect Speech presentation (e.g. The Indirect Speech tag was applied to examples such as the second half of the sentence: Hundreds of protesters and politicians gathered in central Moscow, demanding that Russia halt the invasion.) (see Semino and Short 2004: 52-3 for more detail).

As far as speech reporting clauses are concerned, it is well known that they are normally used to introduce stretches of Direct Speech (e.g. She said in She said: "No") or Indirect Speech (e.g. Labour claimed in Labour claimed that it had recruited another high profile Conservative MP). They typically include a reference to the relevant speaker(s) and a verb referring to speech activity (e.g. "say", "claim", etc.). However, the same introductory function can be performed by non-clausal structures, such as According to one senior officer or calls by IRA hardliners to [. . .]. We therefore used the tag NRS ("Narrator's Report of Speech") to annotate all the stretches of text that perform the function of introducing stretches of Direct Speech, Indirect Speech (and, in a few cases, Free Indirect Speech), regardless of their grammatical structure (see Semino and Short 2004: 35ff; see also Halliday 1994: 263 and Thompson 1996: 518 et passim). Although the examples I will discuss below are all clausal in structure, I will continue to use the acronym NRS, for consistency and ease of reference.

Together, NRSs and NRSAs capture the vast majority of references to speech activity in the corpus. My analysis in this paper is based on concordances containing 2,563 instances of NRS and 985 instances of NRSA respectively (NB: the latter figure is lower than the total figure for NRSA in the corpus given in Semino and Short (2004: 67), since I have excluded all borderline and embedded cases of NRSA. The same strategy was applied to the concordancing of NRSs). In analyzing the concordances, I regarded individual instances of NRS/NRSA as metaphorical when:

(i) one or more of the lexical items that, in context, refer to speech activity have a more basic current sense that is not to do with verbal communication, and

(ii) the speech activity sense of the relevant expressions can be said to be motivated by the more basic sense via a cross-domain mapping where the target is speech activity and the source is a different domain. 
The emphasis on current basic senses in the first criterion above means that I do not include etymological metaphors (e.g. verbs such as "insist", "propose", "express"; see, for example, Sweetser 1987, Traugot and Dasher 2002). However, in her diachronic study of metaphors for thought and speech, Sweetser (1987) found that the same underlying metaphorical mappings were "both synchronically lively and diachronically important in past meaning shifts" (Sweetser 1987: 455; emphasis in original). Although I will not be able to deal with this issue, my own data supports this general observation.

Consider the following example of NRSA from the corpus:

2. The Americans [...] were now bombarding the security man at the front gate with questions about just which building was the actual home of the Benny Hill Show (Smith, J. The Benny Hill Story, 1988, p. 96)

In (2) the verb "bombard" is used to describe the way in which a group of American tourists asked a security man questions about the location of the studio in which English comedian Benny Hill records his show. However, the verb "bombard" has a more basic sense that is not to do with verbal communication, but with the dropping of bombs, typically on military targets. The speech activity sense of "bombard" (which is conventional in English) can be explained in term of a mapping from the domain typically associated with the basic sense of "bombard" (WAR or, more generally, ARMED PHYSICAL AGGRESSION) to the domain of verbal communication. This explains why the use of "bombard" in reference to asking questions suggests a persistent, forceful and possibly aggressive attitude. I will return to this example below.

According to my analysis, 249 instances of NRS out of the total 2,563 examples in the concordance involve metaphorical references to speech activity, amounting to approximately 10 per cent of the total. For NRSA, I analysed as metaphorical 214 out of the total 985 instances included in the relevant concordance, amounting to approximately 22 per cent of the total. The fact that the proportion of metaphorical examples is lower for NRS than for NRSA is largely due to the preponderance of the verb "say" in speech reporting clauses. Overall, therefore, my claims in the rest of this paper are based on the analysis of 463 authentic metaphorical references to speech activity in a balanced corpus of written British English.

The use of corpus data does not, of course, necessarily lead to findings that could not have been arrived at via other methods. However, corpora enable researchers to study naturally-occurring linguistic patterns on a large scale, and therefore tend to provide a greater number and variety of examples than can be generated by intuition or by the analysis of small amounts of data. As a consequence, by adopting a corpus methodology, I aim to place my claims about possible underlying conceptual metaphors on a firm and explicit empirical footing. This will hopefully partly address the concerns expressed in several recent studies about the lack of a rigorous and explicit methodology, within cognitive metaphor theory, for extrapolating conceptual metaphors from linguistic data (e.g. Cameron 1999, 2003: 239-41; Low 1999, 2003; Ritchie 2003, Steen 1999). 


\begin{abstract}
ANALYSIS
I will present my findings by considering in turn each of the main patterns of metaphorical expressions in my data and the source domains they relate to. The ordering of the various sub-section is not based on frequency, however, but on the role played by each source domain in the overall metaphorical scenario that I briefly sketched out above and that I will present in detail at the end of the paper. I will therefore begin by discussing expressions that metaphorically present speech activity in terms of motion, and then go on to consider expressions relating to physical proximity, physical pressure, physical aggression, physical construction, transfer (of objects), and visibility. As will become clear in the course of the discussion, the distinctions between patterns that are discussed in different sections are often not clear-cur, as individual expressions may evoke more than one potential source domain, and the same conceptual material can sometimes be subsumed under different source domains.
\end{abstract}

\title{
Expressions relating to movement
}

A number of studies have shown that, in English, communication is often metaphorically constructed in terms of motion in space, both synchronically and diachronically (e.g. Sweetser 1987, Emanatian 1997, Traugot and Dasher 2002: 190ff., Kövecses 2002: 80). In my data, 35 instances of NRS/NRSA contain expressions that have physical senses relating to movement. As noted in other studies, however (e.g. Sweetser 1987, Vanparys 1995: 26-28), there is considerable variation in the nature of the movement involved, particularly with respect to the entity that is presented as moving, the space where movement takes place, and the destination of the movement.

\section{Movement towards a speech act or the interaction}

In the examples below, the action of taking a turn in conversation or of producing a speech act that others have already produced in the same context is metaphorically expressed in terms of physical approach:

3. John Major also joined the condolences in a message to Mr Howard. (The Independent, 29/4/1996)

4. Mary's father stepped in with congratulations. (A. Huxley, Point Counter Point, 1928, p. 139)

The verb "join" has a basic physical sense relating to moving physical entities towards each other so that they touch or become connected. It also has a more specific physical sense relating to moving towards other people, in order to do things together or to foster emotional intimacy (e.g. I sat down and Katrina soon joined me again, from the BNC). This motivates the conventional metaphorical use of "join" to indicate the act of becoming a member of an organization or a group (e.g. "I joined Amnesty in 1968", from the BNC). In example (3), however, the verb "join" is followed by a direct object indicating a speech act (the condolences). Hence John Major's performance of a speech act that others have already performed in a particular context is metaphorically 
constructed in terms of movement towards the speech act. It could also be argued that "the condolences" refers metonymically to those who have already publicly expressed their condolences, which would bring this particular use of the verb closer to the most conventional metaphorical sense to do with becoming part of a group.

The metaphorical use of "join" in example (3) can be explained in more than one way. If we start from the physical sense of "join" that relates to goal-directed movement, we can see uses such as (3) as instantiations of the primary metaphors "ACTION IS SELFPROPELLED MOTION" (e.g. "I've got to start moving on this project"; Grady 1997: 287) and "ACHIEVING A PURPOSE IS ARRIVING AT A DESTINATION" (e.g. "He'll ultimately be successful, but he's not there yet”; Grady 1997: 286; see also "PURPOSES ARE DESTINATIONS" in Lakoff and Johnson 1999: 52-3). These metaphors, Grady argues, are experientially grounded in correlations between, respectively, "performing an action and moving" and "achieving a purpose and moving to a spatial location" (Grady 1997: 28687). These particular metaphors are also clearly relevant to example (4), where the action of performing a speech act is metaphorically presented, via the verb "step in", in terms of movement into a location. In other words, in (4) the interaction between the characters is constructed as a physical space, so that taking a turn in a conversation corresponds to entering this physical space.

Another possible explanation for example (3) focuses on the fact that the particular kind of movement evoked by "join" results in physical proximity. From this point of view, examples such as (3) can be related to other expressions that construct agreement and solidarity in terms of physical proximity, such as "Whose side are you on?" and "I'll side with him every time”, which Grady (1997: 297) explains via the primary metaphor “AGREEMENT/ SOLIDARITY IS BEING ON THE SAME SIDE”. In example (3), however, it is a commonality of (expressed) feeling, attitude and purpose that is partly constructed as physical proximity. I will return this example in the section where I discuss other expressions that construct spoken communication in terms of physical proximity among participants.

\section{Movement towards or away from the goal of communication}

Some metaphorical NRSAs contain expressions in which speech activity is constructed in terms of movement along a path towards or away from a destination. Consider the examples below:

5. "No, don't misunderstand me," Constance went on. "I was thinking more of myself than her. [...]"

6. Yesterday Mr Haigh [. . . ] back tracked a little (The News of the World, 11/12/94)

In example (5) the reporting clause (NRS) includes a highly conventional metaphorical use of the phrasal verb "go on" to refer to the act of resuming talk or continuing to talk. The verb "go on" is of course conventionally used to refer metaphorically to the continuation of any process, action or behaviour (e.g. "Goldberg went on typing", from the $B N C$ ). This can be explained in terms of the primary metaphors "AN EVENT IS THE MOTION OF AN OBJECT" (e.g. "The concert went until 4 o'clock”; Grady 1997: 286) and 
“ACTION IS SELF-PROPELLED MOTION" which apply generally to events and human activities. Examples such as (5) show that the latter metaphor also applies to speech activity in particular.

Example (6) is an instance of a highly conventional metaphorical use of the verb "back track" to indicate the expression of different and/or weaker views than previously expressed. As suggested earlier, the primary metaphor "ACHIEVING A PURPOSE IS ARRIVING AT A DESTINATION" also applies to conversational purposes. Indeed, English has a number of conventional expressions whereby (successful) communication (or, more precisely, the successful verbal expression of one's thoughts or feelings) is constructed in terms of forward movement towards a destination, as in the following extract from the BNC: “Herr Nordern said 'Get to the point can't you.' 'I'm getting there', Bodo said.". Here the most relevant topic or piece information is presented as the end point of motion along a path. In this context, it is therefore possible to explain how, in examples such as (6), moving backward corresponds to verbally declaring a (partial) change of mind.

A more extended realization of “ACHIEVING A PURPOSE IS ARRIVING AT A DESTINATION" in the context of speech activity is given below:

7. Bunty still has to run through all our names until she reaches mine (Atkinsons, K. Behind the Scenes at the Museum, 1995, p. 280)

Here the first-person narrator, who is the youngest child in her family, talks about how her mother (Bunty) mistakenly says the names of all her other children before finally saying the narrator's own name. This process is metaphorically presented, via the phrasal verb "run through", as rapid movement in space. Here the path along which the movement occurs corresponds to the list of children's names, and the destination is the intended linguistic expression (in this case, the narrator's own name).

\section{Movement without a destination}

All of the expressions I have considered so far in this section present speech activity in terms of intentional, goal-directed motion. This is not the case, however, in the examples below:

8. friends started deserting her as word spread that Ariel had died of Aids. (Today, $5 / 12 / 1994)$

9. In October 1988 stories began circulating that Kylie had been the victim of a crazed sex-attacker. (Stone, S. Kylie Minogue: The Superstar Next Door, 1990, p. 57)

In both examples reference is made to a process whereby an unspecified number of individuals told others about sensitive private information about a particular person, so that, eventually, many people knew about it. In both cases this is presented, from the point of view of the person in question, as apparently uncontrollable and undirected movement on the part of the utterances/texts themselves ("word", "stories"): the verb "spread" has a physical sense to do with substances (such as liquid) moving outwards in 
all directions to cover a large area, while "circulate" has a physical sense to do with entities or substances (such as air) moving around continuously within an enclosed space. It is therefore important to note that, while the other types of expressions discussed above can all be related to the basic PATH image schema, here metaphorical motion does not take place along a path, but outwards from a central point in the case of "spread" and cyclically within a particular space in the case of "circulate". In both cases, the relevant physical movement is normally unintentional and hard to control, and, in both cases, the verbs in question have related metaphorical uses that are not to do with speech activity (e.g. "This problem has spread to the UK", "Even then, Jobs predicts, illegal copies will circulate", from the BNC). While expressions such as these can be related to primary metaphors such as Grady's (1997: 186) “CHANGE IS MOTION” and "AN EVENT IS THE MOTION OF AN OBJECT", they also seem to suggest a more specific metaphorical conceptualization of uncontrollable, harmful events or behaviour in terms of the uncontrollable movement of entities or substances.

Overall, the expressions I have analysed in this section account for 7.5 per cent of all metaphorical instances of NRS/NRSA in my data. They all suggest a conceptualization of spoken communication in terms of motion in space, but, as I have shown, they differ significantly in terms of the precise nature of that motion and the kind of speech activity it is metaphorically applied to. Hence, I have explained them in terms of (a small set of) different primary metaphors.

\section{Expressions relating to physical proximity}

Nine metaphorical NRSAs in my data (i.e. approximately four per cent of all my metaphorical NRSAs) include expressions whose physical senses are to do with physical proximity without contact. Most of these expressions involve metaphorical uses of the verbs "back" and "stand by" as in the extracts below:

10. Afterwards Mr Milosevic [. . .] backed the proposals (The Daily Telegraph, $5 / 12 / 1994)$

11. A vicar who told his congregation "Santa's a fake" stood by his words yesterday. (The Daily Express, 12/12/1994)

The verb "back" has a number of physical senses, the most relevant of which indicates that an entity is positioned (closely) behind another. The verb "stand by" is similar, except for the fact that it indicates standing beside rather than standing behind. Both verbs also have several conventional metaphorical senses, including that of providing assistance, or being ready to provide assistance, in a number of non-physical, generally social, contexts (e.g. "Our Home Care teams are made up of doctors and nurses backed by a network of trained and active volunteers", and "In Hindu families, therefore, often the women members stand by each other in times of stress and distress", from the BNC). Examples such as (10) and (11) show how the metaphorical use of these verbs also applies to communicative interaction (whether the relevant entity is another person, a particular view, a previous utterance, the contents of a text, and so on). 
These examples can be broadly explained with reference to image schemata such as CENTRE-PERIPHERY and NEAR-FAR (Johnson 1987: 124-5). More specifically, they can be related to other types of expressions that Grady (1997) accounts for by means of primary metaphors. "EMOTIONAL INTIMACY IS PROXIMITY" is proposed by Grady in order to explain expressions such as "My sister and I are very close" (Grady 1997: 293). Here the experiential motivation lies in the correlation between being emotionally intimate with someone and being physically close to them (see also "INTIMACY IS CLOSENESS" in Lakoff and Johnson 1980: 52). This metaphor could explain some metaphorical uses of "stand by" in particular, but does not fully explain examples such as (10) and (11). Another potentially relevant primary metaphor is "AGREEMENT/SOLIDARITY IS BEING ON THE SAME SIDE", which, as I mentioned earlier, Grady proposes on the basis of linguistic expressions such as "I'll side with him every time" (Grady 1997: 297). The expressions in my examples, however, evoke physical proximity generally, rather than specifically being on the same side, and, as I have mentioned, also have conventional metaphorical senses that relate to (potential) assistance generally rather than agreement in particular. This could be accounted for by a more general metaphor along the lines of AGREEMENT/SOLIDARITY/(POTENTIAL) ASSISTANCE IS PHYSICAL PROXIMITY, which could in fact also explain the use of "join" in example (3) above.

\section{Expressions relating to physical support}

The corpus contains four NRSAs in which speech activity is metaphorically referred to by means of the word "support", used either as a verb or as a noun. An example is given below:

12. Mr Milosevic supported the plan then, but made little headway in persuading the Bosnian Serbs. (The Independent, 5 December 1994)

Here "supported" does not just refer to Milosevic's positive attitude towards the referent of "the plan", but also to the expression of a positive attitude, which was essential to the realization of the plan in question. A similar use of "support" in relation to written communication is given below:

13. Yet six months earlier he supported the very same regime in a letter to a fellow MP. (Today, 5/12/1994)

In its physical sense, the verb "support" indicates that an entity prevents another from falling via physical contact and mutual physical position. As I mentioned earlier, "support" (both as a verb and as a noun) also has a wide range of conventional metaphorical senses: we conventionally talk about "moral support", "financial support", "political support", and so on. Grady (1997: 283) explains such conventional metaphorical senses by proposing the primary metaphor "ASSISTANCE IS SUPPORT", which, he argues, has its experiential motivation in the correlation between physical support and the continued functionality or viability of physical objects (indeed, Grady (1997: 282) sees "ASSISTANCE IS SUPPORT" as a corollary of "FUNCTIONALITY/VIABILITY IS ERECTNESS", which gives rise to expressions such as "That record still stands"; see also "HELP IS SUPPORT” in Lakoff and Johnson 1999: 52). Grady's linguistic examples of “ASSISTANCE 
IS SUPPORT" do not relate specifically to verbal communication, but to social relations more generally: "Our conservation program needs your support" and "I've really been leaning on my friends the past few months" (Grady 1997: 283). Examples such as (12) and (13) show that the same primary metaphor can also explain the use of words such as "support" to indicate the verbal expression of a favourable attitude towards someone or something, which, in context, may result in the relevant entity achieving its goals, coming into being, continuing to exist, and so on. As is the case with the primary metaphors discussed in the previous sections, it is possible to argue that "ASSISTANCE IS SUPPORT" has an image-schematic basis, particularly with reference to the CONTACT and BALANCE image schemata (Johnson 1987).

\section{Expressions relating to physical pressure}

Eight of the metaphorical NRS/NRSAs in my data evoke a physical scenario where an agent (corresponding to the speaker) comes into contact with another entity (normally corresponding to the addressee) and exercises physical pressure on it. Consider the examples below:

14. when the Mirror continued to press him over the stabbing of estranged wife Nicole (The Daily Mirror, 13/5/96)

15. The UN's military commanders, led by General Sir Michael Rose, have pressed for an end to Nato's aerial presence over Bosnia (The Independent on Sunday, $4 / 12 / 1994)$

In its most relevant physical sense, the verb "press" is to do with physically pushing against another entity. In the above examples, the notion of physical pressure is metaphorically mapped onto that of using language in order to get others to do something that they may not otherwise do, and/or that they may be reluctant to do. In (14), the direct object of "press" (him) refers to the addressee (O. J. Simpson), and the goal is to get him to respond to the allegation that he killed his wife. In (15) object of the the phrasal verb "press for" (an end to Nato's aerial presence over Bosnia) refers to the speakers' ultimate goal, and implicitly reveals the addressee on whom the pressure is exercised (Nato, or more precisely, the countries participating in a Nato-led campaign in Bosnia).

Expressions evoking the notion of physical pressure have a wide range of related conventional metaphorical uses that go well beyond the target domain of communication. For example, we commonly talk of "peer pressure", "moral pressure", "work pressure", and so on. All these expressions can be explained with reference to Grady's primary metaphor "COMPULSION IS A COMPELLING FORCE" (Grady 1997: 287). Of the two linguistic examples that Grady provides for this particular metaphor, one does not relate to communication ("Vanity finally drove me to have the operation"), but the other is to do with the exercising of influence over somebody else's behaviour via speech ("My friends pushed me into volunteering"). Grady identifies the experiential basis of "COMPULSION IS A COMPELLING FORCE" in "the correlation between deliberate action and motion through space" (which is also captured by the COMPULSION image schema; see 
Johnson 1987: $41 \mathrm{ff} .$, Sweetser 1990: 69ff.). In other words, we know from our basic physical experience that others can affect our movements in space by pushing against us, or, conversely, that we can affect others' physical movement in space by pushing against them. This experience is mapped onto more general and less physical experiences where people use a variety of strategies (including verbal strategies) in order to get others to act in ways that they may not want to.

My concordance contains only eight examples of this kind, amounting to approximately 2 per cent of all metaphorical examples in my data. The four expressions involving "support" discussed in the previous section also represent a very small proportion of the metaphorical references to speech activity I have analysed ( 2 per cent of metaphorical NRSAs and 1 per cent of all metaphorical NRS/NRSAs combined). However, as I have explained, both sets of examples are part of much larger patterns whereby assistance of many kinds is metaphorically constructed in terms of physical support, and compulsion of many kinds is metaphorically presented in terms of a physical force exercising pressure. Indeed, since both physical support and physical pressure involve physical contact between entities, these two patterns can be seen as part of the same conceptual scenario, in which physical contact with pressure corresponds to the verbal exercise of compulsion, while physical contact without pressure corresponds to the verbal provision of assistance.

\section{Expressions relating to physical aggression}

In Metaphors We Live By, Lakoff and Johnson (1980) discuss a range common linguistic expressions relating to arguments, such as "Your claims are indefensible", "His criticism were right on target", "I've never won an argument with him". They conclude that "ARGUMENT is partially structured, understood, performed, and talked about in terms of WAR" (Lakoff and Johnson 1980: 5), and therefore propose the well-known conceptual metaphor "ARGUMENT IS WAR". This metaphor, Lakoff and Johnson argue, is based in an experiential correlation between verbal arguments and physical fights, which are common among animals generally, but which humans "have institutionalized [...] in a number of ways, one of them being war" (Lakoff and Johnson 1980: 62; see Kövecses 2002: 74-5 for a "cultural" account of the experiential basis of this metaphor).

In a dictionary-based study of "metalinguistic metaphors", Vanparys (1995) has noted, however, that the English expressions that construct communication in terms of fighting "do not necessarily make reference to a situation of war", and are therefore best accounted for in terms of a more general conceptual metaphor, which he formulates as "VERBAL AGGRESSION IS PHYSICAL AGGRESSION" (Vanparys 1995: 31). More recently, Ritchie (2003) has pointed out that many of the linguistic expressions normally adduced as evidence for "ARGUMENT IS WAR" can also be associated with other potential source domains, such as sports or games like chess and bridge, and therefore proposes that the relevant source domain is best seen as a complex conceptual field relating to different types of conflict, ranging from games through fisticuffs to all-out war (Ritchie 2003: 135). This, he suggests, leads to a stronger account of the experiential basis of the conventional linguistics patterns noted by Lakoff and Johnson: although most (American) native speakers of English do not have first-hand experience of war, they do have direct, first- 
hand experience of many types of less extreme physical conflict, such as physical scuffles among children, physical contests, sports and games. Within this perspective, the fact that physical conflict functions as a source domain for verbal conflict has a clear experiential basis in bodily experience from an early age. In my discussion I will show how the patterns I have identified in my data are indeed more compatible with Vanparys's and Ritchie's proposals than with the traditional "ARGUMENT IS WAR" formulation (see also Semino forthcoming).

Thirty-three references to speech activity in my concordances are realized by expressions that metaphorically present verbal conflict in terms of physical aggression. There is some variation however, in the precise nature of the physical conflict that appears to function as source. Some expressions are similar to those cited by Lakoff and Johnson as evidence for "ARGUMENT IS WAR". The use of the verb "bombard" in example (2) above belongs to this group as do the following expressions: "flare" (in "questions flaring"), "blast" (in "blasting Tory claims that ..." and "flak" (in "flak over fat cat pay"). Three further examples are given below:

16. amid renewed backbench sniping at the Blair style of leadership (The Guardian, $13 / 5 / 1996)$

17. [O]nce again we were firing questions (The Daily Mirror, 13/5/1996)

18. The Chancellor, Kenneth Clarke, yesterday stepped up his guerrilla warfare against the Tory right by insisting that [. . .] (The Guardian, 13/5/1996)

Clearly, it is possible to see such expressions as linguistic realizations of the conceptual metaphor "ARGUMENT IS WAR". However, closer analysis reveals some difficulties. Only some of these examples refer to the expression of critical views in arguments or controversies (e.g. "stepped up his guerrilla warfare against the Tory right"), while others refer more generally to persistent and forceful behaviour in spoken communication, not necessarily within an argument as such (e.g. "bombarding with questions").

Moreover, the literal senses of these expressions do not just relate to war in the sense of organised military conflict among countries, but rather to the wider domain of armed violence, which also includes, for example, the activities of terrorist organisations and of armed criminals generally.

Similar considerations apply to the use of the verbs "attack" and "defend" to refer to speech activities, as in the examples below:

19. Last night M Delors attacked M Balladur's idea of a "Europe of circles" in which each member country could progress at its own speed. (The Daily Telegraph, $12 / 12 / 1994)$

20. The Chancellor also defended his stand on a European single currency. (The Daily Star, 13/5/1996)

Although both "attack" and "defend" can apply literally to the context of war, their literal senses actually relate to physical aggression and violence more generally, as in the following examples from the BNC: Police attacked at acid house parties, and Michael 
told the Old Bailey he had tried to defend his brother Lee, 13, before his father turned on him.

My data also contains a further set of expressions in which speech activity is metaphorically presented in terms of low-level hostile physical action which does not normally involve the use of weapons. Consider the examples below:

21. But Mr Straw hit back: "The changes we are talking about do not necessarily spell the end of the monarchy [. . .]" (The Daily Mirror, 5/12/1994)

22. Ex-Tory chairman Lord Tebbit, in a further swipe at Mr Major, said suspending the rebel MPs was silly (The Daily Express, 12/12/1994)

23. Both presenters have been slammed for fluffing their lines (The News of the World, 11/12/1994)

24. He rapped his decision to remove the whip from eight MPs who voted against the Euro-cash bill last week. (The Daily Star, 5/12/1994)

In all four cases the underlined expressions have basic physical senses to do with the delivery of blows against physical entities, including, in some cases, people. While "hit", "swipe" and "slam" may refer to the delivery of one or more blows against someone or something, the physical sense of "rap" involves repeated, if more gentle, blows to an object, or, in a more restricted sense, somebody else's knuckles (e.g. He told his teacher he had lost it on the way to school, and Mr Watson promptly rapped his knuckles with a ruler for his carelessness, from the BNC). In all four cases, what is being metaphorically referred to is the verbal expression of negative or critical attitudes towards somebody else's views, decisions or behaviour.

The analysis of my data therefore seems to suggest that Lakoff and Johnson's formulation of the conceptual metaphor "ARGUMENT IS WAR" is too restricted. As far as the source domain is concerned, the expressions I have presented do not (or not only) relate to the domain of WAR, but to a more general domain, which, following Vanparys (1995), I will refer to as PHYSICAL AGGRESSION. This domain includes a large variety of forms of aggressive action, from the delivery of blows with one's bare hands to the deployment of the kind of weaponry that is typically used in armed conflict between countries. As far as the target domain is concerned, many of my examples do refer to arguments (even though not necessarily in face-to-face communication), but some relate more generally to critical, forceful, or antagonistic communicative behaviour, which may not be part of an argument as such (e.g. "bombarding with questions" and "firing questions"), or which may not necessarily receive a reply from the addressee (e.g. "Both presenters have been slammed ..." in example 23). It may be more appropriate, therefore, to regard the expressions discussed in this section as realizations of a general conceptual metaphor which may be referred to as "ANTAGONISTIC COMMUNICATION IS PHYSICAL AGGRESSION" . This conclusion is broadly compatible with Vanparys's (1995) and Ritchie's (2003) proposals, but does not deny, of course, that war is a salient part of the complex domain of physical aggression, and that it functions as the specific source of some metaphorical expressions relating to arguments. The problem with the "ARGUMENT IS WAR" formulation is that it does not properly account for the linguistic evidence, and 
tends to force a narrow interpretation of expressions that do not necessarily relate specifically either to (metaphorical) war or to (literal) arguments.

It needs to be noted, however, that, like "ARGUMENT IS WAR", "ANTAGONISTIC COMMUNICATION IS PHYSICAL AGGRESSION" provides a rather general description of the relevant metaphorical mapping(s). In Grady's terms, “ANTAGONISTIC COMMUNICATION IS PHYSICAL AGGRESSION" is a "complex" conceptual metaphor, consisting of the combination of several primary metaphors. Two of the primary metaphors proposed by Grady can be seen as particularly relevant here. The first is "OBJECTING IS ATTACKING" (e.g. examples 16, 18, 19, etc.), and the second is "DAMAGE IS PHYSICAL HARM", which accounts specifically for those metaphorical expressions which suggest that the target of critical or forceful verbal action is being physically damaged or destroyed, as in "blasting Tory claims that ...” and other examples above. In Kövecses's (2002) terms, these primary metaphors can be seen as the central mappings that result from the main meaning focus of the PHYSICAL AGGRESSION source domain. Some of my examples, however, appear to realize a slightly different metaphorical mapping, whereby engaging in persistent, unwelcome (communicative) behaviour towards someone else is constructed as physical attack. These include particularly "bombarding with questions" and "firing questions", as well as, from the receiver's perspective, expressions such as the following from the BNC: "We're still limited by sexism, but at the same time we're bombarded with images telling us that we have to achieve a lot', "The traveller today is bombarded with information about travelling".

With 33 instances, metaphorical expressions drawing from the source domain of physical aggression account for approximately seven per cent of all metaphorical NRS/NRSAs in my two concordances. Not surprisingly, the vast majority of these expressions (27) occur in the press section of the corpus, since news reports are often concerned with disagreements and debates on controversial issues, both of a private and of a public nature. More importantly, the expressions analysed in this section appear to be coherent with those I discussed in the previous sections: speech activities in interaction are metaphorically constructed on the basis of a physical scenario in which (i) physical proximity or physical contact without pressure metaphorically corresponds to a favourable attitude and (potential) assistance, (ii) physical contact with pressure corresponds to the verbal attempt to influence others' behaviour, and (iii) physical aggression and violence corresponds to antagonistic communication. This scenario will be further developed in the following sections.

\section{Expressions relating to physical construction}

The two individual verbs that occur most frequently in my 463 metaphorical references to speech activity are "make" (30 instances) and "add" (54 instances). Both verbs have physical senses that broadly relate to the construction of physical objects.

Consider the example below:

25. the producers duly made a plea for more support for the British film industry. (The Daily Telegraph, 5/12/94) 
The verb "make" is highly delexicalised and has a large number of non-physical conventional senses (e.g. "make a wish", “make a mistake”, "make an attempt”, etc.). However, it is possible to identify a basic, physical sense (i.e. that of physically constructing a concrete object), which can be seen as acting as metaphorical source for non-physical uses (see also Cameron 2003: 72-3). In extract (25), for example, a particular speech act ( $a$ plea) is metaphorically presented as a physical entity that can be constructed in the process of communication. Other similar examples from the corpus include "make an appeal", "make a statement", and "make a disclaimer". In addition, there are a number of expressions where "make" is followed by a direct object referring to a text-type or utterance-type, rather than a speech act (e.g. "make a joke", "make a report", "make a comment"). In other words, the process of verbally producing utterances, texts and speech acts is conventionally referred to via the most basic verb in English for referring to the physical construction of concrete objects (see also Vanparys 1995: 14).

The verb "add" is used slightly differently, as can be seen in the examples below:

26. "But I supposed you'd go on poaching whether you were welcome or not," she added with a nervous little laugh. (Huxley, A. Point Counter Point, 1928, p. 139)

27. Mr Straw - who claimed he had the backing of his leader Tony Blair - ominously added that the changes did "not necessarily spell the end" of royal rule.

(Independent on Sunday, 4/12/1994)

While "make" is mostly used in NRSA constructions, "add" is used exclusively in reporting clauses accompanying Direct Speech (as in example 26) or Indirect Speech (as in example 27). In its most basic physical sense, the verb "add" refers to the process of putting an entity or substance together with other entities or substances (e.g. He then slices open the fillet to add a langoustine mousse, from the BNC). However, apart from its mathematical sense, it is also conventionally used to refer to increases in intensity or to the acquisition of extra qualities, as in the following examples from the BNC: Not to have made a will can only add to that stress and Including scented flowers in the display adds a special touch. Examples (26) and (27) demonstrate an equally conventional metaphorical sense relating to communication, and particularly to the process of resuming talk or saying something similar or relevant to what has been said before.

Although the specific source and target concepts evoked by "make" and "add" in my examples are different, I have grouped these expressions together here because in both cases the (relatively) abstract and intangible process of communicating meanings is metaphorically constructed as a physical process, whereby objects are made and objects/substances are added to other objects/substances. Together, these two verbs are used in 18 per cent of all metaphorical NRS/NRSAs in my data, thereby forming the second largest group of metaphorical expressions after those relating to transfer, which will be discussed next. 


\section{Expressions relating to transfer}

In what has become a classic study in cognitive metaphor theory, Reddy (1979) famously noted that, in English, communication is often talked about in terms of the transfer of objects along a conduit (e.g. "You have to put each concept into words very carefully" and "Try to get your thoughts across better"). Reddy labelled the underlying metaphorical conceptualization of communication "the conduit metaphor" (see also Lakoff and Johnson 1980: 10-12 et passim on what they call "the CONDUIT metaphor"). Within this metaphor, Reddy argued, language "functions like a conduit, transferring thoughts bodily from one person to another"; speakers and writers "insert thoughts or feelings in the words"; words containing the thoughts and feelings are transferred to the addressee(s); and finally listeners or readers "extract the thoughts and feelings again from the words" (Reddy 1979: 170). Reddy estimated that as many as 70 per cent of the expressions speakers of English commonly use to talk about communication are instantiations of the conduit metaphor. More recently, Grady (1997: 119ff., 1998) reanalysed Reddy's linguistic data and proposed that the CONDUIT metaphor should be decomposed into a set of primary metaphors, which also motivate many conventional metaphorical expressions that are not to do with communication.

In my data, the largest single group of metaphorical NRS/NRSAs (93 instances) contain expressions of the kind that led Reddy (1979) to propose the CONDUIT metaphor (see also Semino forthcoming). Two typical examples are given below:

28. Mr Michael Portillo gave warning yesterday that the Tory right could not be united until ... (The Daily Telegraph, 12/12/1994)

29. Kenneth Clarke, the Chancellor of the Exchequer, has delivered a defiant message to restless Tory backbenchers ... (The Observer, 13/5/1996)

In their most basic physical senses, the verbs "give" and "deliver" are to do with to the transfer of concrete objects in the physical world. Their use in examples such as (28) and (29) suggests that the production of texts/utterances and the performance of speech acts are constructed in terms of the transfer of physical objects from one person (the speaker) to others (the addressees). The verbs "give" and "deliver" are the prototypical and most frequently used examples of this group of metaphorical expressions in my data, but several other verbs are used metaphorically in the corpus in very similar ways, including: "issue" (e.g. "issue a command"), "leave" (e.g. "leave a message”), "offer" (e.g. "offer advice"), "pass on"(e.g. "pass on news"), "send" (e.g. "send a message”), and "throw" (e.g. "throw questions").

In Grady's (1997: 25ff, 1998) terms, all these expressions are realizations of the primary metaphor "TRANSMISSION OF ENERGY IS TRANSFER (OF OBJECTS)", which, he argues, is experientially grounded in the fact that the communication of meaning literally involves physical transfer of some sort (e.g. acoustic signals in spoken communication, physical objects in traditional written communication, and so on). In the examples discussed by Reddy and Grady, however, the range of entities that are presented as being transferred in expressions of this kind is restricted to the contents of an utterance/text (e.g. "give evidence", "pass on news") and to what Reddy called "Repertoire Members" (e.g. "give 
views"). In my data, the range of such entities also includes text-types (e.g. "send a message", "deliver a lecture") and speech acts (e.g. "give warning”, "issue a command"). All of these entities are therefore metaphorically constructed as objects that can either be physically transferred from the addresser to the addressee (as in examples 28 and 29) or made available within the communication space so that they are accessible to others (e.g. "issue a command", "leave a message"). The primary metaphor “TRANSMISSION OF ENERGY IS TRANSFER (OF OBJECTS)" therefore also involves a general ontological metaphors whereby RMs, as well as utterances, their contents and their illocutionary force are constructed as physical entities (but not necessarily as possessions in the way suggested by Grady 1997, 1998).

In linguistic terms, all the expressions discussed in this section are light-verb constructions involving conventional metaphorical uses of verbs that are delexicalised to varying degrees. As a consequence, some of these verbs can be used more or less interchangeably. For example, "give" and "deliver" can be used interchangeably with direct objects such as "message", while "give" and "issue" can be used interchangeably with direct objects such as "order". In spite of their delexicalised status, however, I have analysed these verbs as metaphorically used in my data because it is possible in each case to identify a basic, physical sense which can function as source for the conventional metaphorical senses to do with communication (see Cameron 2003: 72-3). Indeed, where the various "transfer" verbs cannot be used interchangeably, the reason seems to lie in the residual influence of their basic physical senses (e.g. "a message" can function as direct object of "give" and "deliver" but is not normally used as direct object of "issue").

The group of examples I classified under the general notion of transfer also includes expressions such as the following:

30. A master asked him on one occasion whether a word was nominative or dative, and back came his answer: "I don't really care, sir!" (Callow, S. Vincent Van Gogh - A Life, 1990, p. 66)

31. He admitted that Labour wanted to reduce the Queen's powers over Parliament (The Daily Express, 5/12/1994)

In example (30) an (impertinent) reply to a question is metaphorically presented in terms of movement back towards the previous speaker. Unlike what I noted in my earlier discussion of expressions to do with motion, therefore, in examples such as (30) conversational exchanges are constructed in terms of an exchange of physical objects between the addresser and the addressee back and forth along a conduit. A similar argument can be made about the use of "admit" in example (31), since the verb still retains the meaning of letting someone or something into a particular space, as in the following examples from the BNC: These gaps admit draughts and dust from the underfloor void and Do not even admit someone claiming to be a policeman or woman. In examples such as (31) the notion of letting someone or something into a physical space is mapped onto that of (verbally) acknowledging as true something that may be detrimental to one's own case and that has usually been said by opponents in an argument. Sweetser (1987) also mentions "admit" as an example of a verb of Latin origin where the 
prefix "ad-" ("(in)to") suggests movement from the speaker to the addressee. In addition, she points out that the presence of the Latin prefix "re-" ("back") in verbs referring to answering (e.g. "reply", "refute") suggests movement in the opposite direction, as is also the case with "back came his answer" in example (30).

Overall, my data contains 93 instances of NRS/NRSAs involving expressions to do with physical transfer. As I mentioned earlier, these expressions constitute the largest group of metaphorical references to speech activity in my data, amounting to 20 per cent of all metaphorical NRS/NRSAs in my concordances. It is also important to notice that the expressions to do with transfer suggest a conceptualization of communication that is broadly compatible with that suggested by the expressions discussed in previous sections - namely as a physical space within which the communication of meanings, the performance of speech acts and the production of utterances/texts are presented in terms of the transfer of physical objects along a conduit from addressers to addressees.

\section{Expressions relating to visibility and visual representation}

Within Reddy's (1979) account of the "CONDUIT" metaphor, meanings correspond to objects and linguistic expressions corresponds to containers, so that understanding corresponds to the emergence of the meanings/contents from the words/containers. This, according to Reddy, accounts for the conventional use of "reveal" in relation to verbal communication in expressions such as "Closer reading reveals altogether uncharacteristic feelings in the story” (Reddy 1979: 193).

My data contains 19 similar examples of the use of "reveal", as well as three uses of the verb "disclose" in expressions such as the following:

32. Whitehall sources last night disclosed that the secret list [. . . played a crucial role in defusing the diplomatic row (The Observer, 13/5/1996)

Like "reveal", the verb "disclose" still retains the (rather archaic) physical sense of making something visible by removing a cover that was hiding it from view (e.g. He cleared away the grass and disclosed a narrow opening descending into the darkness, from the $\mathrm{BNC}$ ).

Grady (1998) explains this kind of expression in terms of the primary metaphor "INFORMATION IS CONTENTS", and goes on to consider "further motivation for the containment image which applies so naturally to linguistic forms" (Grady 1998: 214). He proposes that one salient motivation is the primary metaphor "BECOMING ACCESSIBLE IS EMERGING". He explains the relevance of this metaphor as follows:

There are numerous linguistic examples which reflect a metaphoric association between perceptibility and location outside a container. The motivation for such a metaphor could not be more natural, of course, since perceptibility is literally correlated with location out in the open in so many cases. (Grady 1998: 214) 
Grady (1998) also points out that the well-known conceptual metaphor "KNOWING IS SEEING" is based on the same kind of experiential correlation, and proposes two separate primary metaphors where the source domain involves location outside a container: "PERCEPTIBLE IS 'OUT"” (e.g. "Heat brings out the flavor in the soup") and "ACCESSIBLE TO AWARENESS IS 'OUT", (e.g. "The facts in the case will come out sooner or later") (Grady 1997: 296). In addition, Grady (1997: 297) considers expressions such as "Why did you have to bring that up again?", and puts forward the primary metaphor “ACCESSIBLE TO PERCEPTION/AWARENESS IS 'UP'”, which, he argues, is based on "the correlation between being in a higher position-e.g., at eye level, or out from under an obstruction-and being perceptible" (Grady 1997: 297).

My corpus contains many examples where the expression and reception of meaning in speech is metaphorically presented in terms of visibility and emergence. These expressions differ, however, with respect to how exactly meanings are made metaphorically visible to addressees. I will discuss each of the three main patterns I have identified in turn.

\section{Movement into view}

Twenty of the metaphorical NRS/NRSAs in the corpus can be related to Grady's “ACCESSIBLE TO AWARENESS IS 'OUT”” or “BECOMING ACCESSIBLE IS EMERGING” primary metaphors. However, these expressions suggest a somewhat more complicated picture than that proposed by Grady. Consider the following examples:

33. It is an indication of how low Kylie's emotional defences were during this crisis that - just for once - the intensely personal details of her life suddenly came gushing out (Stone, S., Kylie Minogue: The Superstar Next Door, 1990, p. 55)

34. "You want to -" was all he got out before Paulie snapped, (McDermid, V. Dead Beat, 1992, p. 168)

Both the expressions "come gushing out" and "get out" have physical senses that relate to movement out of a container or a bounded space. However, here it is not the words or the text that correspond to a container. Rather, the speakers themselves (respectively, the pop-singer Kylie Minogue and a character called Dennis) are implicitly constructed as containers, from which meanings come out via language. More precisely, in example (33), the contents of the speaker's utterances (the intensely personal details of her life) are presented as the agent of the movement; in example (34), the speaking character is presented as attempting to get particular meanings out of himself. These examples, therefore, appear to realize both "ACCESSIBLE TO AWARENESS IS 'OUT'/BECOMING ACCESSIBLE IS EMERGING” and “THE BODY IS A CONTAINER” (see also Vanparys 1995: 24-6).

It is not always the case, however, that the metaphorical references to visibility and emergence in my data also involve explicit or implicit references to movement out of containers. My concordances include one instance of the use of "bring up" in the sense of "mention" that was noticed by Grady, as well as examples such as the following: 
35. [S]enior medical staff [...] raised doubts about the accuracy of the Americandeveloped test used in her diagnosis. (The Observer, 28/4/1996

36. But he floated Tom King's suggestion that ... (Thatcher, M. The Downing Street Years, 1993, p. 854)

Example (35) is one of five cases in the corpus where the verb "raise" is used in reference to verbal activity, with direct objects referring to speech acts or to what Reddy calls RMs ("doubts", "alarm", "objections", "questions"). Give that, in its physical sense, the verb "raise" suggests movement from below upwards, its use in my examples can be seen as a realization of Grady's “ACCESSIBLE TO PERCEPTION/AWARENESS IS 'UP”” primary metaphor. Within this perspective, the conventional use of "raise" in relation to communication is based in our visual experience, where, if something is positioned too low, it may be outside the observer's field of vision, so that movement upwards involves movement into view. The conventional use of "float" in example (36) is rather different, but can also be explained in terms of a mapping from visual experience: in its physical sense, this verb involves both permanence on the surface of the water (and hence visibility) and movement with the current (and hence, possibly, towards the addressee and into their field of vision). The corpus also contains two instances of the use of the verb "put forward" in reference to speech activity (e.g. "I put forward the view that"), which seem to work in a similar way.

Clearly, the expressions analysed in this section confirm the correlation, noted by Grady, Lakoff and Johnson and others, between (1) knowledge and vision and (2) the expression of meaning and emergence/movement into view. However, my data shows that what may act as source domain is not just emergence via movement upwards or out of a container, but rather movement towards the addressee more generally. This could be explained in terms of a metaphor along the lines of "ACCESSIBLE TO AWARENESS/CONSIDERATION IS 'IN FRONT" ", which may also motivate, for example, the conventional uses of the verb "face" in expressions such as the following, from the BNC: "We must face the facts" and "The defence establishment is faced with a dual problem". This metaphor has a similar experiential basis as Grady's "ACCESSIBLE TO AWARENESS IS 'OUT" " and "ACCESSIBLE TO AWARENSS IS 'UP'": in visual experience, there is a correlation between the positioning of an object in front of us and our ability to perceive its properties. At a more general level, all these expressions can be related to "KNOWING/UNDERSTANDING IS SEEING", which, according to Grady (1997: 296) has as a corollary "CONSIDERING IS LOOKING AT". On the basis of my examples, I could suggest the converse corollary, namely "ACCESSIBLE TO AWARENESS/CONSIDERATION IS VISIBLE". Together these conceptual metaphors can therefore explain why communication is conventionally metaphorically presented in terms of different types of movements into view.

\section{Pointing}

A further set of 23 examples from my data involve metaphorical references to verbal activity in terms of the physical actions of pointing or indicating: 
37. Officials at the Department of Energy still wanted to commission Pressurised Water Reactors which were an American development, pointing to the success of the French nuclear industry (Adams, J. Tony Benn, 1992, p. 442)

38. Only last Friday John Major pointed out that Labour's plans [. . .] would lead to the break-up of the UK. (The Daily Express, 5/12/1994)

39. Senior Cabinet sources indicated that the rebels would not be offered any more compromises by the government. (Independent on Sunday, 4/12/1994)

In examples (37) and (38), the verbs "point to" and "point out" are used to refer metaphorically to the action of mentioning something that is relevant to and supports the speakers' argument. In example (39) the verb "indicate" is used to refer to the verbal provision of new, relevant information. In all three cases, verbal communication is metaphorically presented in terms of a physical scenario in which speakers make meanings/ideas/facts accessible not by moving them into the addressee's field of vision but by indicating their existence and location to the addressee (in fact, the expression "point out" involves both a metaphorical reference to the physical act of pointing and the notion of emergence from containers in the prepositional adverb "out"). Within this scenario, meanings are therefore constructed as physical entities that are potentially visible but that may not be noticed by the addressee without the speaker's intervention.

The use of these expressions can be related to Grady's (1997: 296) “CONSIDERING IS LOOKING AT" primary metaphor, which he presents as a corollary of "KNOWING IS SEEING", and exemplifies with expressions such as "We'll be taking a good, long look at him as a suspect in this case" (Grady 1997: 296). However, in my examples the focus is on what the speaker/writer does in order to enable the addressee to "look at" the meanings that he or she is trying to convey. The BNC contains many examples of "point out" and "point to" being used in the same ways as in 37 and 38. There are also many examples of the use of the verb "point to" in which the entity presented as the agent of the pointing action is not the speaker/writer but a text or some other entity (e.g. "The evidence [...] pointed to a fire on board the DC-8 before it crashed"). In all these cases whatever is being pointed out/to is not just offered for consideration, but also presented as a true and relevant fact within the relevant discourse context. On the basis of this, I would propose a primary metaphor along the lines of "ENABLING KNOWLEDGE/CONSIDERATION IS POINTING/INDICATING". This metaphor is clearly closely related with both "KNOWING IS SEEING" and "CONSIDERING IS LOOKING AT", and also to Grady's "EXISTENCE IS VISIBILITY". The latter is a primary metaphor that Grady (1997: 284) proposes in order to explain examples such as "The dodo disappeared in the 1600s" and "Rap music first appeared in the late 70s". As Grady puts it, this metaphor is based on "the correlation between our awareness of objects (i.e. knowledge of their existence) and their presence within our field of vision" (Grady 1997: 284). This correlation helps to explain why the use of "point to", "point out" and "indicate" in my examples suggests that whatever is being pointed out/to or indicated is "true": in basic, perceptual experience, if something can be shown via pointing, it can also be seen; if it can be seen, it exists, and is therefore "true".

\section{Visual representation}


The corpus also contains six examples of NRSA in which verbal activity is metaphorically referred to by means of expressions which have basic senses to do with visual representation, as shown below:

40. Mr Jack Straw, the party's home affairs spokesman, outlined proposals to redefine the Queen's role and reduce the size of the Royal Family. (The Daily Telegraph, $5 / 12 / 1994)$

41. Kenneth Clarke, the Chancellor of the Exchequer, has delivered a defiant message to restless Tory backbenchers, portraying himself as a staunch defender of the welfare state. (The Observer, 13/5/1996)

In (40) the verbal expression of particular plans in broad, general terms is metaphorically presented in terms of providing an outline, i.e. a visual representation that shows the outer edges or shape of the represented objects, rather than the details. In (41) the verbal expression of a particular opinion on something (in this case the speaker himself) is metaphorically presented in terms of visual portrayal. Another similar expression contained in the corpus is "to represent (someone or something) as ...". In all these examples the notion of making a visual representation is mapped onto that of expressing particular meanings or opinions in words. In fact, these verbs can be metaphorically applied to the communication of meaning generally (i.e. not necessarily via words), as in the following extracts from the BNC: "Table 18 outlines these limitations" and "The Manor House itself dates from the 13th. century but it has now been restored to portray how this ancient building was the centre of a thriving farm at the turn of the century."

All of these examples may be explained in terms of a conventional metaphorical mapping from the source domain of VISUAL REPRESENTATION to the target domain of COMMUNICATION. The latter is to be intended in the broadest possible sense, i.e. including informing, suggesting, explaining, or generally enabling the construction of particular meanings. This metaphor, which could be referred to as "ENABLING KNOWLEDGE/CONSIDERATION IS PROVIDING A VISUAL REPRESENTATION”, is clearly closely connected with "KNOWING IS SEEING" and the other visual metaphors I have discussed so far.

Overall, therefore, the expressions discussed in the whole of this section construct communication in terms of making visual perception possible in a number of different ways, namely by:

i. moving an entity out of a container, upwards, or towards the addressee;

ii. physically pointing at/indicating something that is potentially visible but may not be seen or noticed by the addressee;

iii. creating visual images that the addressee can see.

The corpus also contains the following interesting example, which does not fall under any of the patterns above, but which is clearly related to them: 
42. After Claudie had reluctantly and shamefacedly put him in the picture about Cardinal's Wharf, he became really interested. (Worsthorne, P. Tricks of Memory. An Autobiography: Peregrine Worsthorne, 1993, p. 125)

Here the first person narrator's wife is talking to a doctor about a mysterious illness that is affecting her husband. Part of this involves explaining the unhygienic conditions in which they live in Cardinal's Wharf in London. This explanation is metaphorically referred to by means of the conventional expression "putting (someone) in the picture". Here a visual representation ("the picture") seems to correspond to the meanings or contents that are being communicated, and the speaker's role is presented as physically placing the addressee inside the picture. In other words, in this expression the meanings or contents themselves are presented as a container or a bounded region which can be entered in order for understanding to take place. Once again, the relevant experiential basis seems to be the correlation between being able to see something and knowing about it, so that speech activity is metaphorically presented as enabling others to see (see Vanparys 1995: 16-17 for more examples).

In her study of the historical development of verbs for mental and verbal activities, Sweetser (1987: 448) notices that mental verbs often come from the domain of physical vision (e.g. "see"), while speech act verbs do not. My data shows that, indeed, some speech activity verbs have physical senses to do with enabling vision. This suggests a coherent metaphorical scenario in which knowledge/understanding is constructed in terms of visual perception, and communication (which enables knowledge/understanding) is constructed in terms of enabling visual perception.

Cumulatively, the different types of expressions relating to visibility and emergence discussed in this section account for 77 examples of NRS/NRSAs in my concordances, amounting to 16.5 per cent of all metaphorical references to speech activity in my data. This represents the third largest group, after expressions to do with the transfer of objects ( 20 per cent) and with the physical construction of objects (18 per cent). By adding together the different types of expressions that Reddy would have subsumed under the CONDUIT metaphor (i.e. those to do with transfer and visibility/emergence), we can therefore account for 36.5 of all metaphorical NRS/NRSAs in my data and just under five per cent of all the references to speech activity I analysed. Although this is a substantial proportion of metaphorical NRS/NRSAs in my concordances, it is considerably less than Reddy's estimate that 70 per cent of all commonly used expressions for communication in English are realizations of the CONDUIT metaphor. As I have shown in the course of the paper, English has a much larger variety of conventional expressions for (spoken) communication than Reddy (1979) noticed (see also Vanparys 1995 for a similar conclusion).

\section{CONCLUSIONS}

The overall picture

The patterns I have discussed in this paper account for approximately 74 per cent of all metaphorical NRSs and NRSAs in my data (i.e. 343 of the 463 NRS/NRSAs that I 
analysed as metaphorical out of the 3,548 occurrences included in the two concordances from the corpus). I do not have the space here to discuss the remaining 26 per cent of my metaphorical data, which includes some further patterns (e.g. the metaphorical use of mental verbs such as "observe", and of verbs evoking animal behaviour, such as "snarl" and " $\underline{\mathrm{COO}}$ "), as well as many individual expressions that do not appear to be part of larger patterns (e.g. "crack jokes", "have a go at"). Table 1 provides an overview of the numbers of occurrences of expressions evoking each of the source domains I have discussed, and of the percentage of cases they represent out of all metaphorical NRSs, all metaphorical NRSAs, and all NRSs and NRSAs combined.

The table shows that the expressions relating to the transfer of objects form the largest group, followed by expressions to do with the production of physical objects, and expressions to do with visibility and visual representation. The remaining patterns are less frequent, but each does account for a non-negligible proportion of all metaphorical references to speech activity in my data. More importantly, however, I have shown that some of the patterns that are less frequent in my data (e.g. those to do with physical pressure and support) are actually part of much larger metaphorical patterns in English that apply to a wide range of target domains beyond spoken communication.

Table 1 - Number of occurrences of expressions belonging to different metaphorical patterns, and percentages of all metaphorical NRSs, NRSAs and NRS/NRSAs combined.

\begin{tabular}{|l|l|l|l|}
\hline Source domains & $\begin{array}{l}\text { Metaphorical } \\
\text { NRSs } \\
\text { (reporting clauses) }\end{array}$ & $\begin{array}{l}\text { Metaphorical } \\
\text { NRSAs } \\
\text { (narrators } \\
\text { representation of } \\
\text { speech acts) }\end{array}$ & Totals \\
\hline Transfer & $48(19 \%)$ & $45(21 \%)$ & $93(20 \%)$ \\
\hline $\begin{array}{l}\text { Production of } \\
\text { physical objects }\end{array}$ & $57(22.5 \%)$ & $27(13 \%)$ & $84(18 \%)$ \\
\hline $\begin{array}{l}\text { Visibility and visual } \\
\text { representation }\end{array}$ & $49(20 \%)$ & $28(13 \%)$ & $77(16.5 \%)$ \\
\hline Movement & $21(8.5 \%)$ & $14(6.5 \%)$ & $35(7.5 \%)$ \\
\hline Physical aggression & $6(2.5 \%)$ & $27(13 \%)$ & $33(7 \%)$ \\
\hline Physical proximity & - & $9(4 \%)$ & $9(2 \%)$ \\
\hline Physical pressure & $1(0.5 \%)$ & $7(3 \%)$ & $8(2 \%)$ \\
\hline Physical support & - & $4(2 \%)$ & $4(1 \%)$ \\
\hline Other & $67(27 \%)$ & $53(26.5 \%)$ & $120(26 \%)$ \\
\hline Totals & $249(100 \%)$ & $214(100 \%)$ & $463(100 \%)$ \\
\hline
\end{tabular}

Overall, my analysis has shown that complex domains such as spoken communication are metaphorically structured by a set of different source domains. These source domains tend to (i) have an image-schematic basis, (ii) have a wide metaphorical scope, and (iii) structure one or more particular aspects of the target via their own most salient and distinctive aspects. More specifically, the complexity of target domains such as speech 
activity results from the fact that it includes a wide variety of aspects, namely elements, processes, actions, relationships and goals. Many of these aspects are shared by other target domains, and are therefore metaphorically structured by the same (aspects of the same) source domains. For example, as I have shown, one aspect of the domain of spoken communication is the provision of help/assistance to others via speech, which can be expressed metaphorically in terms of physical support. The notion of help/assistance, however, is also part of many other areas of experience (e.g. family relationships, interpersonal relationships generally, sports, politics, economics, and so on), and can therefore be expressed in terms of physical support in relation to many different target domains, as others have pointed out (e.g. Grady 1997, Lakoff and Johnson 1999). One way of capturing these more general patterns that cut across many different areas of experience is via Grady's primary metaphors, which, as I have shown, can often explain both the patterns I found in my data and the fact that the same expressions can also be applied to domains other than speech activity. As I mentioned earlier, Kövecses (2002) accounts for the same phenomena via the notion of central mappings that project the main meaning focus of wide-scope source domains onto a wide range of target domains.

In my analysis I also identified the main aspects of speech activity that tend to be constructed metaphorically, the source domains that are involved in each case, and the wider applicability of the sets of expressions resulting from each source domain. For example, a central aspect of the domain of speech activity is the expression of meanings so that others can understand them. This aspect, as Reddy (1979) originally noted, is metaphorically constructed in terms of the transfer and visibility of objects, which, as Grady (1998) has pointed out, are also applied to the expression and understanding of meaning generally, i.e. not just via speech or language. Another central aspect of the domain of speech activity is the expression and negotiation of mutual relationships, which are metaphorically constructed via expressions to do with physical proximity, support and pressure. These expressions are also conventionally applied to social interaction and relationship generally, i.e. not simply in the context of verbal communication. A more specific aspect of speech activity is the expression of negative attitudes in order to cause damage to others and their goals. This aspect is metaphorically constructed in terms of expressions to do with physical aggression which also apply to other areas of experience involving negative attitudes and negative effects. In addition, the production of messages and speech acts is presented in terms of the physical notions of making concrete objects and adding to them, which conventionally apply to many abstract processes and entities. And finally, the achievement of goals in and via speech is constructed in the same ways as goals more generally, i.e. as destinations to be reached.

As a consequence of all this, I have argued that the most appropriate level of abstraction for the formulation of conceptual metaphors is that of primary metaphors, which capture simple mappings that participate in the construction of many complex target domains. This results in a more exhaustive and accurate view of linguistic patterns, and of possible underlying conceptual mappings, than any generalizations that start from complex target domains (e.g. "SPEECH ACTIVITY IS ...” or “COMMUNICATION IS ...”). This approach also results in a more economical and cognitively plausible account of how metaphorical mappings might be stored in conceptual structure, since a relatively small number of 
simple and basic mappings can explain the production and reception of a very large number of linguistic expressions in many different contexts.

At the same time, this approach can also lead to more reliable accounts of the metaphorical structuring of particular target domains. Although the conceptual metaphors that motivate the different linguistic patterns are not always consistent with one another, the main patterns I have identified can be combined into a coherent single conceptualisation of spoken communication in terms of a physical space containing entities corresponding to the interactants, their speech acts, their utterances/texts, their views/ideas, and so on. Within this space:

- interactants can move in or out, towards or away from other participants, speech acts, conversational goals (e.g. "step in with congratulations", "join the condolences", “backtrack”);

- interactants can be positioned in different ways in relation to each other (e.g. "back", "stand by");

- interactants can come into physical contact with each other in different ways, i.e. with or without pressure (e.g. "press", "support") or engaging in different types of physical aggression (e.g. "rap”, "hit out”, "blast”);

- speech acts and texts/utterances can be physically constructed ("make a plea"), added to (" $\underline{\text { add") }}$ ) and transferred from addressers to addressees (e.g. "give an order", "deliver a speech").

- texts/utterances, their contents, or their illocutionary force can become visually accessible to the addressee via different types of movement (e.g. "came gushing out", “raise doubts”), pointing (e.g. "point to"), or visual representation (e.g. “outline”).

I am not suggesting that the above scenario "exists" as a single conceptualization in the minds of any, let alone all, speakers of English. What I am suggesting is that the main patterns I have identified in my data seem to indicate that speech activity is conceptualised in English in terms of a range of physical actions and interactions which, at a general level, are compatible with each other and can be integrated into a single scenario.

\section{Final methodological considerations}

The last few years have seen a rise in the use of electronic corpora in metaphor research (e.g. Boers 1999, Cameron and Deignan 2003, Deignan 1999, 2000; Peters and Wilks 2003, Semino 2002, Semino et al. 2004). These studies show how the adoption of a corpus-based approach, coupled with an explicit and rigorous identification procedure (e.g. Cameron 2003: 58ff.), can lead to important advances in our understanding of metaphorical patterns in language, and also place the extrapolation of conceptual metaphors from linguistic evidence on a much firmer empirical footing than it has been in the past.

In the present study, the adoption of a corpus methodology has enabled me to arrive at results that are, I believe, more exhaustive and reliable than those obtained on the basis of introspection and/or the random collection of examples. First, my data was obtained from a balanced and representative quarter-of-a-million word corpus of (late) $20^{\text {th }}$ century 
written British narrative texts. Second, the fact that the corpus was annotated for forms of SW\&TP provided me with a fairly large number of relevant examples $(3,548$ references to speech acts/activity, of which 463 were analysed as metaphorical). Third, I systematically used a larger corpus (the 100-million word British National Corpus) in order to provide examples of other (not speech-related) uses of the expressions under analysis (see Cameron and Deignan 2003 and Semino 2002 for a similar combination of smaller and larger corpora in metaphor research). All this has enabled me to notice a larger and richer variety of metaphorical linguistic patterns for speech activity than had been observed before, which in turn has put me in a better position to make claims about possible underlying conceptual metaphors. I have also been able to compare the frequencies of different patterns of metaphorical expressions in my data. Inevitably, however, the overall picture I have proposed can only be an advance on what previous studies have achieved, and will in turn need to be further refined and completed by further, large-scale analyses.

\section{Notes}

\footnotetext{
${ }^{1}$ I am grateful to Zoltan Kövecses, Alan Cienki, Ray Gibbs and an anonymous reviewer for their feedback on an earlier draft of this paper. I am also grateful to the British Academy for funding the project of which this study is part (grant LGR-37225).

${ }^{2}$ I am indebted to Zoltan Kövecses for pointing out the similarity between my findings and his.
} 


\section{References}

Austin, J. L. (1962). How to Do Things with Words. Oxford: Oxford University Press.

Bach, K. and Harnish, R. M. (1979). Linguistic Communication and Speech Acts. Cambridge, Mass.: M.I.T. Press.

Ballmer, Th. and Brennenstuhl, W. (1981). Speech Act Classification: A Study in the Lexical Analysis of English Speech Activity Verbs. Berlin: Springer-Verlag.

Boers, F. (1999). When a bodily source domain becomes prominent: the joy of counting metaphors in the socio-economic domain. In R. W. Gibbs Jr. and G. J. Steen (Eds.), Metaphor in Cognitive Linguistics (pp. 47-56). Amsterdam: John Benjamins.

Cameron, L. (1999). Operationalising "metaphor" for applied linguistic research. In L. Cameron and G. Low (Eds.), Researching and Applying Metaphor (pp. 3-28). Cambridge: Cambridge University Press.

Cameron, L. (2003). Metaphor in Educational Discourse. London: Continuum International Publishing.

Cameron, L. and Deignan, A. (2003). Combining large and small corpora to investigate tuning devices around metaphor in spoken discourse. Metaphor and Symbol, 18, 3, $149-60$.

Deignan, A. (1999). Corpus-based research into metaphor. In L. Cameron and G. Low (Eds.), Researching and Applying Metaphor (pp. 177-99). Cambridge: Cambridge University Press.

Deignan, A. (2000). Persuasive uses of metaphor in discourse about business and the economy. In C. Heffer and H. Sauntson (Eds.) Words in Context: A Tribute to John Sinclair on his Retirement (pp. 156-68). Birmingham: ELR Discourse Analysis Monograph No. 18.

Emanatian, M. (1997). The Spatialization of Judgment. In W.-A. Liebert, G. Redeker and L. Waugh (Eds.) Discourse and Perspective in Cognitive Linguistics (pp. 131-147). Amsterdam: John Benjamins.

Goosens, L., Pauwels, P., Rudzka-Ostyn, B., Simon-Vandenbergen, A.-M. and Vanparys, J. (1995). By Word of Mouth: Metaphor, Metonymy and Linguistic Action in a Cognitive Perspective, Amsterdam: John Benjamins.

Grady, J. (1997). Foundations of meaning: primary metaphors and primary scenes. Unpublished Ph.D. dissertation. University of California, Berkeley.

Grady, J. (1998). The "Conduit" metaphor revisited: A reassessment of metaphors for communication. In J-P. Koenig (Ed.), Discourse and Cognition: Bridging the Gap (pp. 205-18). Stanford, CA.: CSLI Publications.

Grady, J. (1999). A typology of motivation for conceptual metaphor: correlation vs. resemblance. In R. W. Gibbs Jr. and G. J. Steen (Eds.), Metaphor in Cognitive Linguistics (pp. 79-100). Amsterdam: John Benjamins.

Halliday, M. A. K. (1994). An Introduction to Functional Grammar ( $2^{\text {nd }}$ edition). London: Edward Arnold.

Heywood, J., Semino, E. and Short, M. (2002). Linguistic metaphor identification in two extracts from novels. Language and Literature, 11, 1, 35-54. 
Johnson, Mark, (1987). The Body in the Mind: the Bodily Basis of Meaning, Imagination and Reason. Chicago: Chicago University Press.

Kövecses, Z. (2000a). Metaphor and Emotion: Language, Culture and Body in Human Feeling. Cambridge: Cambridge University Press.

Kövecses, Z. (2000b). The scope of metaphor. In A. Barcelona (Ed.) Metaphor and Metonymy at the Crossroads: A Cognitive Perspective (pp. 79-92). Berlin: Mouton de Gruyter.

Kövecses, Z. (2002). Metaphor: A Practical Introduction. Oxford and New York: Oxford University Press.

Lakoff, G. and Johnson, M. (1980). Metaphors We Live By. Chicago: Chicago University Press.

Lakoff G. and Johnson, M. (1999). Philosophy in the Flesh: The Embodied Mind and its Challenge to Western Thought. New York: Basic Books.

Low, G. (1999). Validating metaphor research projects. In L. Cameron and G. Low (Eds.), Researching and Applying Metaphor (pp. 48-65). Cambridge: Cambridge University Press.

Low, G. (2003). Validating Metaphoric Models in Applied Linguistics. Metaphor and Symbol, 18, 4, 239-54

Pauwels, P. and Simon-Vanderbergen, A.-M. (1995). Body parts in linguistic action: underlying schemata and value judgements. In L. Goosens, P. Pauwels, B. Rudzka-Ostyn, A.-M. Simon-Vandenbergen and J. Vanparys, By Word of Mouth: Metaphor, Metonymy and Linguistic Action in a Cognitive Perspective, (pp. 3569). Amsterdam: John Benjamins.

Peters, W. and Wilks, Y. (2003). Data-Driven Detection of Figurative Language Use in Electronic Language Resources. Metaphor and Symbol, 18, 3, 161-73.

Reddy, M. J. (1979). The conduit metaphor: a case of frame conflict in our language about language. In A. Ortony (Ed.), Metaphor and Thought ( $2^{\text {nd }}$ edition) (pp. 164201). Cambridge: Cambridge University Press.

Ritchie, D. (2003). "ARGUMENT IS WAR"- Or is it a game of chess? Multiple meanings in the analysis of implicit metaphors. Metaphor and Symbol, 18, 2, 125-46.

Searle, J. R. (1979). Expression and Meaning. Cambridge: Cambridge University Press.

Semino, E. (2002). A sturdy baby or a derailing train? Metaphorical representations of the euro in British and Italian newspapers. Text , 22, 1, 107-39.

Semino, E. forthcoming. A corpus-based study of metaphors for speech activity in contemporary British English. In S. T. Gries and A. Stefanowitsch (Eds.) Corpora in Cognitive Linguistics: Conceptual Metaphors. Amsterdam: John Benjamins

Semino, E., Heywood, J. and Short, M. (2004). Methodological problems in the analysis of metaphors in a corpus of conversations about cancer. Journal of Pragmatics, 36, 7, 1271-1294.

Semino, E., Short, M. and Wynne, M. (1999). Hypothetical words and thoughts in contemporary British narratives. Narrative 7, 3, 307-34.

Semino, E. and Short, M. (2004). Corpus Stylistics: Speech, Writing and Thought Presentation in a Corpus of English Writing. London: Routledge.

Steen, G. J. (1999). From linguistic to conceptual metaphor in five steps. In R. W. Gibbs Jr. and G. J. Steen (Eds.), Metaphor in Cognitive Linguistics (pp. 57-77). Amsterdam: John Benjamins. 
Sweetser, E. (1987) Metaphorical Models of Thought and Speech: A Comparison of Historical Directions and Metaphorical Mappings in the Two Domains. In J. Aske, N. Beery, L. Michaelis and H. Filip (Eds.) Proceedings of the Thirteenth Annual Meeting of the Berkeley Linguistics Society (pp. 446-59) Berkeley, Ca: Berkeley Linguistics Society.

Sweetser, E. (1990) From Etymology to Pragmatics: The Mind-as-Body Metaphor in Semantic Structure and Semantic Change. Cambridge: Cambridge University Press.

Taylor, J. R. (2002). Cognitive Grammar. Oxford: Oxford University Press.

Thompson, G. (1996). Voices in the text: Discourse perspectives on language reports. Applied Linguistics 17, 4, 501- 530.

Traugot, E. C. and Dasher, R. B. (2002) Regularity in Semantic Change. Cambridge: Cambridge University Press.

Vanparys, J. (1995). A survey of metalinguistic metaphors. In L. Goosens, P. Pauwels, B. Rudzka-Ostyn, A.-M. Simon-Vandenbergen and J. Vanparys, By Word of Mouth: Metaphor, Metonymy and Linguistic Action in a Cognitive Perspective, (pp. 1-34). Amsterdam: John Benjamins.

Wynne, M., Short, M. and Semino, E. (1998). A corpus-based investigation of speech, thought and writing presentation in English narrative texts. In A. Renouf, A. (Ed.), Explorations in Corpus Linguistics (pp. 231-45). Amsterdam: Rodopi. 